\title{
Ullrich Congenital Muscular Dystrophy
}

National Cancer Institute

\section{Source}

National Cancer Institute. Ullrich Congenital Muscular Dystrophy. NCI Thesaurus. Code C123438.

A rare, autosomal recessive inherited disorder caused by mutations in the COL6A1, COL6A2, and COL6A3 genes. Signs and symptoms usually appear at birth or early infancy. Affected individuals have severe muscle weakness, multiple contractures, and hypermobility in their distal joints. 